\title{
Doctoral Students' Transition to the Academic Culture of Foreign Universities: Setting the Stage for $\mathrm{PhD}$
}

* Dr. Syed Abdul Waheed, Assistant Professor (Corresponding Author)

\begin{abstract}
International doctoral students' journey towards their PhD studies begins with finding an appropriate research supervisor and making a transition to the academic environment in a foreign university. The successful academic transition eventually determines the success of doctoral students. The present study aims to examine doctoral students' experiences of searching for a supervisor, seeking their colleagues' support for integration into the university and to describe their experiences of shifting to a relatively different field of study. Thirteen Pakistani doctoral students were purposively selected to explore their lived experiences of making the transition to Austrian universities. The Phenomenological research approach guided the present study. The data collected through interviewing the participants was thematically analyzed that lead to the emergence of the themes; finding a supportive supervisor, developing a research proposal, support for transition and transition to a different field. The themes revealed that it was hard and by chance to get a supportive supervisor while being in another country. Doctoral students' colleagues supported them to explore the institutional environment that helped them integrate into the university. Nevertheless, shifting to a relatively different field of research was challenging and slowed down the process of transition. The research has implications for prospective doctoral students for adequate preparation before entering into a foreign university.
\end{abstract}

Keywords: Academic Transition, Austrian Universities, Academic Environment, Socio-academic Introduction Integration, $\mathrm{PhD}$, Doctoral Students, Pakistan

Academic culture and educational opportunities vary across the countries. The difference becomes more prominent in the developing and developed countries of the world. These distinctions emerge as a result of the socio-cultural and academic conditions of a country (Khanal \& Gaulee, 2019). Consequently, "doctoral programs differ between countries, institutions, and disciplines in terms of their structure, development process and taught element" (Janta, Lugosi, \& Brown, 2014, p. 553). The international students, in this perspective, struggle to accommodate themselves in another cultural setting that is not consistent with their own culture (Alloh, Tait, \& Taylor, 2018; Khanal \& Gaulee, 2019). Lea and Rice (2007) argued that "these difficulties run from students being ignored to verbal insults and confrontation" (p. 405).

In this perspective, the transition and academic integration become significantly important in doctoral students' academic and professional life as an early career researcher. A supervisor is the first person who facilitates in making a transition in an academic culture supported by the institutional faculty and administration. Therefore, the selection of the supervisor becomes crucial in the life of doctoral students (Phillips \& Pugh, 2000). In other words, selecting a supervisor indirectly determines doctoral students' topic of the dissertation, conceptual framing and methods of conducting research that falls in the supervisors' field of study and this directs the nature of their mutual relationship as well (Schiff \& Ryan, 1996). The doctoral students become conscious in selecting a supervisor of their 'choice' (Alloh, Tait, \& Taylor, 2018; Khanal \& Gaulee, 2019).

Nevertheless, the situation becomes critical if the students could not receive desired support from the host university because in certain universities, the supervisor is not professionally prepared and trained to direct such research activities. It is noticed that the teaching faculty is intensely engaged in their instructional activities and they can hardly find the time for advising their students (Pechar \& Thomson, 2004). Also, the students do not have the opportunities to learn from the seminars,

* Department of Educational Research \& Assessment, Faculty of Education, University of Okara, Pakistan Email: s.a.waheed@uo.edu.pk 
colloquiums, and symposiums and they are deprived of the initial support in their research field. Thus, their level of engagement and motivation is decreased, that led them to academic and social isolation (Alloh, Tait, \& Taylor, 2018). Such students take more time in seeking support, integrating into the academic environment and completing their degrees.

The students coming from another academic culture and educational background required to gain an understanding of how they should interact and work with the students and colleagues from other academic cultures and how they should find an appropriate research supervisor to avoid changing a topic, field of study and shifting to another supervisor. Such students experience anxiety and feel stress at the time of commencement of their studies that may prolong in some cases (Van Maanen, 1977, 1984). To get involved in the academic activities and scholarly pursuits they feel the need to be supported by the already working research groups and forums of the university (Weidman, Twale, \& Stein, 2001).

It implies that the situation becomes worse when the master level students from a developing country like Pakistan enter into an institute of higher learning for a higher degree or doctorate in a techno political and academically advanced country like Austria. The students in this scenario have difficulties in adjusting and integrating into the socio-academic culture of the university. This situation leads the students to struggle in finding themselves in a "new world" of academia and thus, they are challenged in meeting the demands of a relatively new academic system.

Austria and Pakistan portray various distinctive features in academic, cultural, social, religious and academic domains. Shoukat (2013) compares the social and academic circumstances in these countries. She states that in Pakistan, teachers keep a distance from the students to represent themselves as more authoritative persons and most of them do not engage the students in academic activities and establish a strict discipline in the class. While in Austria, teachers are deeply involved with the students to encourage them to participate in the learning process. It can be assumed from the results of her doctoral dissertation on Pakistani and Austrian adult learners' learning styles in socioacademic perspectives that Pakistani students would likely face challenges in making the transition to Austrian universities where the education system has a comparatively different value system.

The doctoral students' transition to another academic environment is a function of how students' characteristics and background information, their knowledge of the supervisor's expertise, their previous research output, their relationship with the supervisors and university support system interplay to help make a smooth transition. The present research study focused on the Pakistani doctoral students' journey towards Austria for studying in public sector universities who had completed their master studies either from Pakistan or from another country. The study examines how did these students make an attempt to adjust themselves and what challenges they had to face while changing their field of studies, academic department, research supervisors and interacting with a culturally different academic and scholarly community in these universities.

\section{Theoretical Framework}

The university and its constituent administrative and academic entities comprising of the scholarly communities such as faculty, peer and other scientific and technical colleagues are significantly important in facilitating doctoral students' transition and integration in the host institute (Golde, 2005; Nerad \& Miller, 1996). Tinto's (1993) interactionalist model, in this perspective, has been acknowledged in several research studies that explored the phenomenon of persistence in doctoral programs (Earl-Novell, 2006; Herzig, 2002; Hoskins \& Goldberg, 2005; Ivankova \& Stick, 2007).

Doctoral students' who spend most of their time in institutional activities depend on the scholarly communities who support them in adjusting to the academic culture of the department while interacting with them. Tinto's (1893) theory of socio-academic integration explains how such students make a transition into the local academic communities. This integration model has five components: pre-entry attributes (student attributes, educational experiences, student background, and financial resources), entry orientation (goals, commitments, financial assistance, and external commitments), Institutional experience (academic and social system of the department/program), Integration (academic and social), research experiences and outcome (dropout/completion). From this theory, the pre-entry attributes and outcomes were employed by Andrew (2004) in the PhD thesis to predict the academic achievement of the students enrolled in a physical therapy program. In the present study, the researcher used institutional experiences and pre-entry attributes of doctoral students to explain the 
phenomenon of their transition to a doctoral program, their field of study and to the institute where they work and study. A 'background data questionnaire' was employed to gather students' pre-entry attributes and this data assisted in elaborating on their transitional experiences in public sector universities of Austria.

\section{Research Questions}

The following research questions were designed to explore doctoral students' experiences of academic transition in public universities of Austria:

1. How did finding a supervisor and supervisory support help doctoral students make a transition in Austria universities?

2. How were doctoral students supported by the academic communities of the institute for transition in Austria universities?

3. How did doctoral students' change in the field of study influence their transition in the academic environment of the universities?

\section{Methodology}

This phenomenologically-oriented study delved into the lived experience of what it is like to make a transition into an Austrian university from the perspective of Pakistani doctoral students. Therefore, the researcher intended to grasp an in-depth understanding of the perspectives of doctoral students on their everyday lived experiences of transition after they entered the host university (van Manen, 1984; Creswell, 2007). According to van Manen (2014), "Lived experience names the ordinary and the extraordinary, quotidian and the exotic, the routine and the surprising, the dull and the ecstatic moments and the aspects of experience as we live through them in our human existence" (p. 39). Van Manen (1997) remarked that lived experience is temporal and "can never be grasped in its immediate manifestation but only reflectively as a past presence" (p. 36). Experiences described by doctoral students turn into lived experiences while living through and processing them cognitively (Smith, Flowers, \& Larkin, 2009). The participants assigned meanings to their experiences and reflected on the questions asked by the researcher. Burch (1990) asserts that "meaning does not lie in the experience. Rather, those experiences are meaningful, which are grasped reflectively" (p. 134).

\section{Selecting and Interviewing Participants}

The participants were thirteen Pakistani doctoral students studying in Austrian universities who were selected purposively. They were informed about the possibility and terms of their participation, minimum time required for the interview and that their experiences would be treated within the framework of research ethics during interviewing and kept confidential afterward. The study participants who had different characteristic demographic information were selected to notice the diversity of their experiences in making the transition to the host university. This variation in participant background information allowed a rich investigation into the nature of transition (Bogden \& Biklen, 1998).

The selected study participants were approached to gain an understanding of the transitional experiences through a semi-structured interview guide. The participants were interviewed at their place of convenience after requesting and gaining their permission to interview. The face-to-face interviews were conducted in the office of the doctoral students at their workplace within the universities. Some of the interviews were undertaken through Skype in video mode as the participants were studying in other cities of Austria and it was not feasible to physically approach them in a mutually agreed time and place.

\section{Data Analysis}

The data were collected and transcribed. The process of the analysis entails determining the essence of the phenomenon through participants' reflection on their transitional experiences (van Manen, 1997). It was focused on exploring the underlying meanings of participants' transition into their academic department, a doctoral program and their integration in the university environment. The interview transcripts were gone through several times to grasp the nature of the hidden sense of what participants described during the interview and discovered the possible themes.

Wholistic and highlighting approaches of text analysis were used to derive themes from the interview transcripts (van Manen, 1997). The transcripts were analyzed in its entirety while listening to the audio recording and reading the text repeatedly for exploring participants' experiences as a whole through the wholistic approach. Concurrently, the transcripts were frequently read to highlight 
and mark the words, phrases, and statements that reflected the phenomenon of interest. The participants' typical words and phrases were also quoted in the results section to highlight the core meanings of their description. The emergent themes were interpreted with the context and background information of the participants to reveal the underlying meaning structures of the phenomenon.

\section{Results}

It was found that doctoral students faced many difficulties, challenges and obstacles at the initial stage of their studies, mainly in the first and second semesters of their academic session. This hindered the process of transition. They described their experiences of choosing a supervisor, searching for an appropriate field of study, the topic of interest and looking for support from the academic colleagues of the institute. Changing the supervisor, topic of the dissertation, and shifting from one department to another department determined the way they made a transition in the university. Hence, the themes; finding a supportive supervisor, developing a research proposal, support for transition and transition to a different field of study were explored from the transcripts and interpreted in the following section.

\section{Finding a Supportive Supervisor}

The selection or allocation of a research supervisor is very crucial in pursuing a doctoral dissertation and it determines students' journey towards the completion of their research. The participants of the study were of the view that this process involves "risks, threats, and uncertainties" and one needs to very cautious while choosing a supervisor in the relevant field of study. They argued that this choice becomes more pivotal when international students are not in physical contact with the potential supervisor. Knowing about the personality, the accessibility and willingness of the supervisor were hard to assess while being in another country and waiting for the approval of a visa. Maryam experienced this situation when she was looking for a supervisor while sitting at home in Pakistan. She was in the $5^{\text {th }}$ semester of $\mathrm{PhD}$ when she was interviewed and she did her MA in a European country. She reflected:

It is not possible to predict if your potential supervisor is socially good while looking at the publications in his/her CV. If I am living in Pakistan and corresponding with the supervisors in Austria, how would I know that he/she would be the best choice without physically interacting with him/her... It is a sort of gambling... You know.

Taking about the indigenous students she added, "Indigenous students already enrolled here take feedback from different sources about a possible supervisor before choosing as his/her supervisor." On the contrary, a few other students experienced that finding a supervisor in one's field of interest is sometimes tricky even after enrolled in a university. Danyal spent a whole year in a department looking for the funding or scholarship and after two semesters, he had to shift to another department and have to search for a relevant supervisor who can also grant him funding or scholarship. He inferred from his experience that a doctoral student must get a confirmation before entry into a university. Danyal could not get acceptance from a supervisor before arriving at the university. He reflected:

It was due to the cooperation of both the supervisors that I was able to find a new supervisor in another department that was relevant to my master's degree as well. I must have to go back to my country if I would not have the opportunity to receive acceptance from a new supervisor.

Some of the doctoral students were required to gain acceptance in the area of their master studies from an Austrian university that would qualify them to acquire a scholarship from HEC, Pakistan. This did not allow them to find a supervisor of their choice and to opt for a new field of study other than the area of specialization in their master's degree. Later on, a few of the doctoral students had to change their supervisor to work in the new area of research they desired before seeking acceptance. In the pressure of getting a scholarship, it was problematic for the students to get an acceptance in an area in which they did not want to work anymore as they intended to research in an emerging area of interest different to their masters. In this case, Ismaeel had to opt a specific field of research merely to furnish the required acceptance to HEC that enabled him to receive the scholarship. He was not at all interested in that area, but he had to continue. He was in the $7^{\text {th }}$ semester of $\mathrm{PhD}$ in the broader field of engineering and technology. He stated ironically: 
It was my bad luck that my supervisor himself was not specialized in the area of my interest. It was unusual for me. I had to work out by reading enormous literature in my field. Unfortunately, Pakistani students are not well prepared before coming to Austria... I think.

Although most of the doctoral students had difficulty in searching the supervisor and finding one who was specialized in the area of their interest, they were mostly supported and facilitated by their supervisors after they reached their respective universities. Haris faced many problems in getting admission to a technical university in Vienna. He got employed in an Austrian Institute before his arrival, but his employer did not guide him well in seeking admission to $\mathrm{PhD}$. Nevertheless, his supervisor was provided him very generous support and helped him to adjust to the "new field of study". His supervisor was personally engaged in helping him to solve the admission problems. He described, "One day, my supervisor stood in a queue for 45 minutes in front of the admissions office along with me... and waited for our turn to get my problem solved."

Similar to Haris' supervisor, Ibrahim was lucky to find a very cooperative supervisor who helped him looking for scientific collaboration for his research project. Such collaborations deal with financial issues when an institute has fewer resources to meet the expenses of laboratory equipment and other necessities. He was doing $\mathrm{PhD}$ in a broader discipline of biological and medical sciences and his department did not have the facility to experiment in the laboratory. His supervisor sought the opportunity of collaboration. Ibrahim described:

It was surprising that she traveled with me to request for the collaboration. We discussed with the other university and my supervisor showed deep concerns on behalf of me to make that collaboration successful. She was doing that in my benefit and I was grateful to her.

$\mathrm{t}$ was encouraging for the doctoral students that most of the supervisors did not compel them to work what they want them to do or the way they must do it. The supervisors allowed them to work independently and they did not interfere in their study decisions. This made their journey towards $\mathrm{PhD}$ worthwhile and they kept on moving. Yasmin was in the $4^{\text {th }}$ semester studying in a technology university and she was encouraged by her supervisor to do an additional degree. She described that "My supervisor has given me much independence for decision making... It was due to my supervisor's support that I decided to continue Master's studies in another university along with my PhD."

It can be inferred that participants faced diverse problems in finding and adjusting to the supervisor in the initial months but most of them were helped out by their supervisor in the study matters and some of the supervisors assisted them personally that encouraged them to make the transition possible.

\section{Developing a Research Proposal}

Doctoral students' formal interaction with the supervisor begins while working on the research proposal that sets the journey towards doctoral dissertation and gives direction to their mutual relationships. This also determines the prospects of students' transition and integration into the academic culture of the department. The policy of doctoral program, departmental support mechanism, supervisor's attitude towards students and their interest in the proposed topic drove doctoral students' experience of working on research proposals. Some of the students were also required by the university to publish their research proposals publically that allowed the students to interact with other academicians in their area. For presenting and defending the research proposal, Maryam had to pass many courses during her $\mathrm{PhD}$ in a university of economics in Austria. She described in this perspective that normally finalizing a research proposal requires nearly two years and:

Its process involved a bureaucratic mechanism requiring much time for its finalization. Also, it was very challenging for a doctoral student to address all the objections and changes suggested by the concerned faculty who reviews the proposal after it is published on the departmental webpage.

Such a proposal goes through a vigorous process of scrutiny by a committee consisting of four professors and the supervisor and co-supervisor who evaluate the proposal. This involves a lengthy process of paperwork and assessment by the panelists that leads to the constitution of a doctoral committee who further process it and give recommendations. It was asked from Ibrahim that how do you perceive this long proses of defending the proposal? He remarked that "It requires extraordinary hard work because different people review the proposal from different perspectives and 
one has to respond accordingly." This prolonged engagement slows down to proceed to the execution of the study and students experience hurdles to make a smooth transition.

This type of online publication is almost similar to receiving reviews on a research paper submitted to a conference or a research journal for publication. One of the study participants Daud experienced that responding to the feedback and review from the evaluators of a manuscript is very "hard business" and it requires high cognitive and technical skills and extensive work that enables the researcher to learn a lot out of this process from the most experienced and learned researchers in the field. The process becomes more intense if someone is publishing in a very high impact factor journal. He reflected on these experiences:

A doctoral student must practice writing a research paper for a possible publication in a journal. It is an outcome of the PhD. In comparison to the conference, a research paper has more impact on many readers around the world that is easily accessible. I was pleased to find a supervisor who was very keen on getting the papers published and he was a great evaluator.

It can be inferred from the participants' experiences that defending a research proposal successfully means that you have "reached the half-way of your research project" that encourages the students to get integrated into the academic environment and establish a positive relationship with the peers and colleagues. Waseem, who was in the $4^{\text {th }}$ semester of his $\mathrm{PhD}$ in the field of social science, gave the credit of defending his proposal to the commitment of his supervisor and support from his colleagues working in the institute. He perceived that "only five percent doctoral students in my department become successful in defending their proposals and I was one of those lucky persons. It could never happen without the support of my supervisor."

Contacting a supervisor, having many lengthy discussions on the proposed research topic, preparing for the presentation of the research proposal and defending it with the help of scholarly communities of the department paves the way to integrate and make a smooth transition into the academic culture of the universities. The students feel pleased and establish relationships with the departmental colleagues that further assist them in their journey to the completion of their dissertation. This first step of formal interaction with the supervisor and other professors is significant in determining the attrition or persistence of the students.

\section{Support for Transition}

The departmental communities are significantly crucial in support of the integration and transition of international doctoral students in a foreign university. These communities include supervisors, other professors in the faculty, doctoral colleagues or peers, scientist, technical and administrative staff and other professionals of the department. It was noticed that they supported doctoral students in adjusting to the academic and social life of the department. In the present study, the student participants found themselves in a multicultural environment that supported them as well.

For example, Yousuf experienced cooperation and close connections with the students from other cultures who supported him to get into the studies. He was studying in the $5^{\text {th }}$ semester in a veterinary university and reflected, "You meet people who have come from different cultures and you share about each other's culture" that supports to adjust in a short period. He got to know students from Muslim countries such as Albania, Iran, and Egypt who shared common cultural values as compared to the indigenous students who had different "language, culture, values, and food". He added, "These restrictions of being culturally different keep us separate from 'them'."

Nevertheless, associating oneself only to the people form one's own culture prohibits students' transition into the local culture. Yasmin was enrolled in a $\mathrm{PhD}$ program of a technology university who experienced that "we restrict ourselves to our 'own culture and religion which is not helpful for us". She noticed that if we want to integrate, we have to understand the local values and we cannot "grow" unless we integrate into the local community. She added:

I think everyone can survive in the university with a little effort. But it is very important to allow yourself for professional development and growth. My perspective is that I should professionally be firm so that I can impart the learned skills to my people when I shall go back to my country.

In consistence with the experiences of Yousuf, who found a diversity of cultures supportive to him, Haris was assisted by his colleagues in the department despite he had changed his field of 
research. He reflected, "You don't encounter language barriers and other problems if you don't know your field because people coming from different cultures have different levels of knowledge and interpersonal skills". The scholars from a different research background in his department presented a diversity of areas of research. Also, the doctoral students from other departments contributed through sharing their own experiences that supported him to transit into his new area of research. In this context, he experienced that "There is a variety of audience and sometimes I get useful hints even from the questions of a 'layman'... you get a chance to think in multiple directions."

Similarly, Ibrahim got the opportunity to interact with the international doctoral students from other countries from whom he learned not only knowledge about his field of research but also new norms and values of dealing with multicultural perspectives that raised his confidence to engage himself in the research communities in his field. He explored:

Presenting a research proposal in a seminar or to a research group enables someone to have an in-depth theoretical, methodological and practical understanding of the research. And most importantly, one listens to many people and tends to improve one's proposal from the perspective of others' expertise and skills relevant to one's work.

Lectures and workshops conducted by international visiting professors provide a huge opportunity to come across the tradition of knowledge in other cultures and he described that it gives "exposure and we know what other people are doing and we remain up-to-date about the ongoing research projects."

One of the study participants Yasmin was working in a research project independent of his supervisor's research group. Yet, she had academic ties with the members of that group and learned many research skills whiles being in her office and regularly interacting with them. This changed his working style and stimulated her to think innovatively about her research project. She supported the arguments of working with other colleagues and remarked, "One of my colleagues was from Hungary. He was doing a side business and I learned from him how to maintain a balance between work and business..." Working in her office was much beneficial as compared to working in isolation at her apartment. She added:

Benefitting from this diversity of cultures and academic traditions was possible only due to visiting my office regularly and interacting with my colleagues. I can feel a difference by comparing myself to a scholar who is working at home. I had feelings of something lost on the day when I don't visit my office.

These cross-cultural relationships and conversations with the international scholars assisted participants to integrated into the academic culture of the university. This cultural, academic and intellectual diversity among the international doctoral community in a university helped Pakistani students to find their way to integrated and make a 'better' transition into a relatively new field of study and new academic culture.

\section{Transition to a 'Different Field' of Study}

The participants of the study described during the interviews that they did not foresee the academic culture of the foreign university and did not plan accordingly that hindered their pace from integrating into the local culture. They were of the view that changing the field of study on arriving in Austria was a disaster for them that wasted their time and energy and it slowed down their transition process. This theme describes participants' experiences of what challenges they faced and how they came over the difficulties when they changed their department, the field of study, or the topic of $\mathrm{PhD}$ research project. In this perspective, Danyal changed had to change his department within the same university. He was doing PhD in the field of Physics in one of the oldest universities in Vienna. He changed the department to get a $\mathrm{PhD}$ in a specific discipline rather than earning a $\mathrm{PhD}$ in an interdisciplinary field that did not work well in Pakistani academic culture He stated:

My first year was a sort of experimentation and learning out of others' and my own experiences. This was a disaster for me as my first year was entirely wasted because I chose another supervisor from another department after one year... I had to start from the beginning. I took one year to understand what was happening with me.

Some of the participants changed their field as they were interested in discovering something "new" than what they had already done in their master thesis. Haris took a risk to research something "entirely new in a different field" and he was confident to explore this new field of study. He 
described, "My supervisor asked me on my arrival that you were free for six months... He didn't suggest to me what I should do." As a result of this freehand, he worked without any pressure in this new field of research and tried to explore what he wanted to do. He added, "My supervisor left me to read up on my 'new' field of study... and the system supported me... This is how to make a PhD student an independent researcher". Nevertheless, despite working in very low work pressure, Haris had to work hard to research in this new field. After working for more two years, he experienced:

Don't you think how much it would have been difficult for me? Indeed, it was challenging to work in a relatively new field of research. It could be much easier if the topic of my research would be related to what I had already done in my master thesis.

It suggests that a previous understanding of the field makes things much easier in making the transition. The doctoral students had different experiences due to the different background of research. One of the PhD students Yasmin changed her PhD topic twice within a year. She had got an acceptance on a research proposal three years before she came to Austria and now, she thought it was not worthwhile to research it as new findings had emerged so far. The second time, she changed the department and came back to the first supervisor as his previous supervisor was "highly ambitious, had high expectations and demanded higher capabilities" form her and she could not come up to that level. She reflected:

It was not an easy job for me to come up to the level of his expectations. I assessed that I could not meet those expectations. At the same time, he could not reach my level of understanding. It was a misfit. Because I did not have background knowledge in that area of research.

Another doctoral student Younus changed his topic of research with the broader area of research. It was not entirely a new topic but it was a topic somewhat related to the previous one but he had not studied the course relevant to this topic. Therefore, he had to attend summer schools, send his research paper in conferences and journals and thus got an understanding of this topic because of the feedback he received from the experts in this field. It realized him how one can explore a field "independently" when his supervisor did not have expertise. Unfortunately, there was no one expert on this topic from any other department in his university, there was no relevant research group, doctoral or post-doctoral researcher and even it was not an area of his supervisor. He reflected:

No one could tell me that "you are thinking in the right direction". Nevertheless, I strived and managed to work independently on my research project by vetting my idea and getting reviews on my research papers from other research forums outside of the university.

Yaqoob, had a different experience as well. His "actual" supervisor referred him to work with his junior colleague in another research group where most of the researchers were working in a funded project and they had their resources and equipment for researching. Yaqoob had the feeling that he was being treated as a member of an "out-group" because he was not working in the area of that project. At this point, he thought he would not be able to complete his $\mathrm{PhD}$ in the given period if he continued working on his topic. He decided to work on the topic, which was consistent with the ongoing research project of that group. Therefore, he requested to change the topic and find a place in the running research project. He changed the topic and it took about eight or nine months to install the required equipment under that project and started working. Among a few other doctoral students, he was one who wasted more than 6-9 months during the first year of the $\mathrm{PhD}$.

The participants of the study who underwent a change in the field or topic, changed the academic department or supervisor did not have a research background in that new area or topic that lead them to face different challenges and they had to work hard to research in the new field with the help of the experts within and outside of the university.

\section{Discussion}

Students' doctoral journey towards their destination of dissertation completion begins with searching for an appropriate supervisor and setting the stage for doing $\mathrm{PhD}$ with his/her support for developing a viable research proposal and meanwhile exploring the institutional environment through seeking opportunities of help from other colleagues working in the university. It was explored that doctoral students had to face many challenges during the first couple of semesters and it intervened in their struggle to make a transition into the host universities' academic culture. This finding is consistent with the research study executed by Hechanova-Alampay, Beehr, Christiansen, and Van Horn (2002), 
who revealed that the international students in America experienced stress during the first six months while studying in the institutes of higher education. Also, Andrade (2006) unveiled that host and international students were challenged with socio-academic issues in the first year of their studies.

Selecting a supervisor before arriving in the host university is one of the significant aspects of making a transition to a foreign university. The participants experienced that it is hard to assess the sociability and degree of expertise of a supervisor in a relevant field of study when doctoral students are living in their home country and requesting for the acceptance from the potential supervisor (Alloh, Tait, \& Taylor, 2018; Bista, 2016; Khanal \& Gaulee, 2019; Phillips \& Pugh, 2000).

Despite selecting a supervisor, some of the participants of the study experienced a mismatch with their supervisor that lead them to seek another supervisor and had to change the topic in a few cases. It was because a few of the doctoral students had to get acceptance from an irrelevant supervisor merely to get a scholarship from their home country. Ives and Rowley (2005) argued that "an academic match between the supervisor's expertise and the student's $\mathrm{PhD}$ topic usually forms the basis for supervisor allocation" (p. 541) that was not noticed among few doctoral students who participated in the present study. Yet, most of the participants were supported by their supervisors and they were integrated into the academic system of the university.

The other studies reveal that a student-supervisor misfit produces negative experiences among doctoral students that demotivate them for further studies (Alloh, Tait, \& Taylor, 2018; Bista, \& Gaulee (2017); Golde, 2005; Hoskins \& Goldberg, 2005; Khanal \& Gaulee, 2019; Tinto, 1993). The contradiction in the way of thinking between student and supervisor have the consequences of withdrawal from the doctoral degree (Golde, 2005) that was not observed in the present study. Also, the state of incongruence between the student and supervisor results in disengagement (Hakanen, Bakker, \& Schaufeli, 2006). Nevertheless, the doctoral students in the present study were not found to be disengaged because they were appreciated and supported by the academic communities of the institute mainly supervisory support did not allow them to disengage from the academic activities. This did not even affect the student-supervisor relationships in most of the cases. Nevertheless, few students experienced a 'bad' relationship that resulted in a change of supervisor and affected their performance to some extent (Hilmer \& Hilmer, 2007; Khanal \& Gaulee, 2019).

It was noted that more than fifty percent of doctoral students had opted for a relatively new topic for their $\mathrm{PhD}$ dissertation that required to gain new knowledge and expertise in the methodology. Nevertheless, the doctoral students were found to be resilient while making a transition and adjusting themselves to the new area of study and they were supported by the scholarly communities of the institution. The other studies also resonate with these findings. Sadlak, Lincoln, Dumitrescu, Maria-Ana, and Popa (2004) noted that designing the research proposal in a field of study and defending before the experts required a great deal of in-depth knowledge, theoretical understanding, and methodological skills which is guided by the supervisors. Ziman (1993) described that "the heart of the $\mathrm{PhD}$ experience is the psychological transition from a state of being instructed on what is already known to a state of personally discovering things that were not previously known" (p. 16).

Some of the participants in the study realized the risk of wasting time if they changed their topic of research or supervisor because they had limited time for the completion of $\mathrm{PhD}$ due to having a scholarship for a stipulated time. This result is confirmed from the study conducted by Appel and Dahlgren (2003) who investigated Swedish doctoral students and found they did not accept to change the supervisor because of the risk that has to start their dissertation from the beginning due to change of supervisor.

\section{Conclusion}

Doctoral students were challenged in seeking supervisors of their choice while being in their home country but they compromised with it after they arrived at the Austrian universities. The first year of their study was found to be crucial as they experienced the challenge of transition into a relatively different academic culture particularly for the Pakistani students who were exposed to the first international journey. Nevertheless, most of the doctoral students were supported by the scholarly communities of the university. The change of supervisor, department, or field of study was challenging but it was supported by the university system and the students made the transition with their determination, resilience, and assistance from others. Most of the students who changed their 
topic or field of study experienced challenges due to a lack of background knowledge of the new area different from their master's degree. In this perspective, few students experienced mismatch with their supervisor that was resolved through negotiating with the prevailing situation. The socio-cultural and academic diversity were found to be supportive of their transition and integration into the socioacademic environment of the department and the university. It was noted that doctoral students' most of the transition experiences were driven by the type of doctoral program, the nature of their relationship with the supervisor, supervisory support and their affiliation with the scientific and administrative communities of the university.

\section{Ethical Considerations}

The participants of the study were accessed before interviewing them for seeking their consent to interview them and to take permission for recording the interview through a digital voice recorder. They were assured that confidentiality would be maintained during the whole research process and afterward. The integrity of the participants was assured through transcribing the interviews by the researcher that helped to reduce the probability of disclosing the personal identification of the participants. The transcripts were coded to conceal individuals' identity and pseudonyms were used with quoted statements to protect their identifications. The Pakistani doctoral students had friendly relationships with each other and their personal information and markers of identification were dealt with utmost care to avoid any harm in the future. The data gathered from the participants in the form of information sheets, consent forms, voice recordings, and transcripts were kept in safe custody to minimize the risk of personal disclosure and threat to their personal or academic life.

\section{Implications for Research and Practice}

Transition to a different academic culture was one of the main themes of the study that needs to be explored through a longitudinal study by investigating doctoral students' long journey and seeking the nature of their transition, challenges and support by the institute at different stages and to examine how do each stage shapes the degree and nature of the transition and socialization of doctoral students. Also, a specific study needs to be undertaken to investigate how doctoral students' theoretical knowledge and research skills affect their prospect in facing challenges and how the selection of new topic different to their master degree hinder their transition and doctoral journey towards completion.

Wastage of an initial couple of semesters was a function of the selection of an inappropriate supervisor. Therefore, most of the doctoral students either changed the supervisor or their topic of $\mathrm{PhD}$. This indicates a lack of planning and a deep consideration of the proposed topic before the initiation of the studies. The Higher Education Commission (HEC) and OeAD should arrange information seminars on how to select a supervisor in the area of interest and how the doctoral degree could be made consistent with the area of research in students' master's degree. This would help students save their initial time, the resources spent during this time and to avoid the wastage of money, loss of energy and minimize the suffering of student-supervisor mismatch.

\section{References}

Alloh, F. T., Tait, D., \& Taylor, C. (2018). Away from home: A qualitative exploration of health experiences of Nigerian students in a U.K. Journal of International Students, 8(1), 1-20. doi: 10.5281/zenodo.1101024

Andrade, M. S. (2006). International students in English-speaking universities: Adjustment factors. Journal of Research in International Education, 5, 131-154.

Andrews, A. W. (2004). Cognitive, collegiate, and demographic predictors of success in graduate physical therapy education. Unpublished dissertation for a doctorate in Education at North Carolina State University, USA.

Appel, M. L. \& Dahlgren, L. G. (2003). Swedish doctoral students' experiences on their journey towards a PhD: Obstacles and opportunities inside and outside the academic building. Scandinavian Journal of Educational Research, 47(1), 89-110.

Bista, K. (2016). Examining the research on international students: Where are we today? Journal of International Students, 6(2), I-X.

Bista, K., \& Gaulee, U. (2017). Recurring themes across fractal issues facing international students: A thematic analysis of 2016 dissertations and theses. Journal of International Students, 7(4), 1135-1151. doi: 10.5281/zenodo.103598 
Bogdan, R. C., \& Biklen, S. K. (1998). Qualitative research for education: An introduction to theory and methods. Boston: Allyn and Bacon.

Burch, R. (1990). Phenomenology, lived experience: Taking a measure of the topic. Phenomenology + Pedagogy, 8, 130-160.

Creswell, J. W. (2007). Qualitative inquiry and research design: Choosing among five approaches. (2nd ed.). Thousand Oaks, CA: Sage.

Dabrowa-Szefler, M. (2001). System ksztalcenia doktorantów w Polsce - próba oceny na podstawie badan ankietowych [System of doctoral studies in Poland - Preliminary analyses of poll data]. Nauka i Szkolnictwo Wyzsze, 1, 62-76.

Delamont, S., Atkinson, P., \& Parry, O. (2005). Supervising the doctorate. A guide to success. Glasgow, UK: Bell \& Bain Ltd.

Donald, J. G., Saroyan, A. \& Denison, D. B. (1995) Graduate student supervision policies and procedures: a case study of issues and factors affecting graduate study.The Canadian Journal of Higher Education, 25(3), 71-92.

Earl-Novell, S. (2006). Determining the extent to which program structure features and integration mechanisms facilitate or impede doctoral student persistence in mathematics. International Journal of Doctoral Studies, 1, 45-57.

Golde, C. M. (1998). Beginning graduate school: Explaining first-year doctoral attrition. In M. S. Anderson (Ed.), The experience of being in graduate school: An exploration (pp. 55-64). San Francisco, CA: Jossey-Bass.

Grover, V. (2007). Successfully navigating the stages of doctoral study. International Journal of Doctoral Studies, 2, 9-21.

Hakanen, J. J., Bakker, A. B., \& Schaufeli, W. B. (2006). Burnout and work engagement among teachers. Journal of School Psychology, 43(6), 495-513.

Hechanova, R., Beehr, T. A., \& Christiansen, N. D. (2003). Antecedents and consequences of employee's adjustment to overseas assignments: A meta-analytic review. Applied Psychology: An International Review, 52, 213-236.

Hechanova-Alampay, R., Beehr, T. A., Christiansen, N. D. \& Van Horn, R. K. (2002). Adjustment and strain among domestic and international student sojourners. School Psychology International, 23(4), 458.

Herzig, A. H. (2002). Where have all the doctoral students gone? Participation of doctoral students in authentic mathematical activity as a necessary condition for persistence toward the $\mathrm{PhD}$. Educational Studies in Mathematics, 50, 177-212.

Hilmer, C. E., \& Hilmer, M. J. (2007). On the relationship between student-advisor match and early career research productivity for agricultural and resource economics PhDs. American Journal Agricultural Economics, 89(1), 162-75.

Hoskins, C. M., \& Goldberg, A. D. (2005). Doctoral student persistence in counselor education programs: Student-program match. Counselor Education and Supervision, 44(3), 175-188.

Ivankova, N. V., \& Stick, S. L. (2007). Students' persistence in a distributed doctoral program in educational leadership in higher education: A mixed-methods study. Research in Higher Education, 48(1), 93-135.

Ives, G. \& Rowley, G. (2005). Supervisor selection or allocation and continuity of supervision: Ph.D. students' progress and outcomes. Studies in Higher Education, 30(5), 535-555.

Janta, H., Lugosi, P., \& Brown, L. (2014). Coping with loneliness: A ethnographic study of doctoral students. Journal of Further and Higher Education, 38(4), 553-571, DOI: 10.1080/0309877X.2012.726972.

Khanal, J., \& Gaulee, U. (2019). Challenges of international students from pre-departure to poststudy: A literature review. Journal of International Students, 9(2), 560-581.

Kragh, S. U., \& Bislev, S. (2005). Universities and student values across nations. Journal of Intercultural Communication, 9, 48-63.

Lee, J. J. \& Rice, C. (2007) 'Welcome to America? Perceptions of neo-racism and discrimination among international students. Higher Education, 53, 381-409. 
Li., J., Wang, Y., Liu, X., Xu, Y., \& Cui, T. (2018). Academic adaptation among international students from East Asian countries: A Consensual qualitative research. Journal of International Students, 8(1), 194-214. doi: 10.5281/zenodo.1134289

Li, S., \& Zizzi, S. (2018). A case study of international students' social adjustment, friendship development, and physical activity. Journal of International Students, 8(1), 389-408. doi: 10.5281/zenodo. 113431

Muhar, A., Visser, J. \& Breda, J. V. (2013). Experiences from establishing structured inter- and transdisciplinary doctoral programs in sustainability: A comparison of two cases in South Africa and Austria. Journal of Cleaner Production, 61,122-129.

Myburgh, C., Niehaus, L., \& Poggenpoel, M. (2002). International learners' experiences and coping mechanisms within a culturally diverse context. Education, 123(1), 107-129.

Nerad, M., \& Miller, D. (1996). Increasing student retention in graduate and professional programs, in J. G. Haworth (Ed.), Assessment Graduate and Professional Education: Current Realities, Future Prospects (pp. 61-76). San Francisco: Jossey-Bass.

Smith, J. A., Flowers, P., \& Larkin, M. (2009). Interpretive phenomenological analysis: Theory, method and research. London: Sage Publications.

Pechar, H., \& Thomas, J. (2004). Austria In Sadlak, J., Lincoln, D., Dumitrescu, Maria-Ana., \& Popa, V. (Eds.). Doctoral studies and qualifications in Europe and the United States: Status and prospects, UNESCO-CEPES studies on higher education. Metropol: Bucharest.

Phillips, E. \& Pugh, D. (2000) How to get a PhD: A handbook for students and their supervisors ( $3^{\text {rd }}$ ed.,) (Buckingham, UK, Open University Press).

Sadlak, J., Lincoln, D., Dumitrescu, Maria-Ana., \& Popa, V. (Eds.). (2004). Doctoral studies and qualifications in Europe and the United States: Status and prospects, UNESCO-CEPES studies on higher education. Metropol: Bucharest.

Sarkakis, K. (2004, May 14). Why I believe PhD students should be paid to study. The Times Higher Education Supplement, p. 14.

Schiff, F. \& Ryan, M. (1996). Ethical problems in advising theses and dissertations. Journalism \& Mass Communication Educator, 51(1), 23-35.

Shoukat, L. (2013). A comparative study of learning styles of Pakistani and Austrian adult learners in socio-academic perspective. Unpublished dissertation for a doctorate in Philosophy at KarlFranzen-Universität Graz, Austria.

Tinto, V. (1993). Leaving College: Rethinking the causes and cures of student attrition (2nd ed.). Chicago: The University of Chicago Press.

Van Maanen, J. (1977). Experiencing organization: Notes on the meaning of careers and socialization. In J. Van Maanen (Ed.), Organizational careers: Some new perspectives (pp. 15-45). London: Wiley and Sons.

Van Maanen, J. (1984). Doing new things in old ways: The chains of socialization. In J. L. Bess (Ed.), College and university organization: Insights from the behavioral sciences (pp. 211-247). New York: New York University Press.

Van Manen, M. (1984). Practicing phenomenology writing. Phenomenology \& Pedagogy, 2(1), 3669.

Van Manen, M. (1997). Researching lived experience: Human science for an action sensitive pedagogy. London, Ontario: The Althouse Press.

Van Manen, M. (2014). Phenomenology of practice: Meaning-giving methods in phenomenological research and writing. CA: Left Coast Press, Inc.

Weidman, J. C., Twale, D. J., \& Stein, E. L. (2001). Socialization of graduate and professional students in higher education: A perilous passage? San Francisco: Jossey-Bass.

Wisker, G., Robinson, G., Trafford, V., Warnes, M., \& Creighton, E. (2003). From supervisory dialogues to successful PhDs: Strategies supporting and enabling the learning conversations of staff and students at the postgraduate level. Teaching in Higher Education, 8(3), 383-397.

Ziman, J. (1993, July 16). Competition undermines creativity. The Times Higher Education Supplement, p. 16. 